\title{
Performance of serum-free broth media for growth of Renibacterium salmoninarum
}

\author{
Clifford E. Starliper ${ }^{1, *}$, William B. Schill ${ }^{1}$, Jay Mathias ${ }^{2}$ \\ ${ }^{1}$ National Fish Health Research Laboratory, U.S. Geological Survey, Biological Resources Division, 1700 Leetown Road, \\ Kearneysville, West Virginia 25430, USA \\ ${ }^{2}$ The Conservation Fund, Freshwater Institute, PO Box 1746, Shepherdstown, West Virginia 25443, USA
}

\begin{abstract}
Growth of Renibactenum salmoninarum was compared in 14 different broth media; 13 serum-free, and 1 that contained newborn calf serum, KDM2+M. Supplementation with $1 \% \mathrm{v} / \mathrm{v}$ R. salmoninarum MCO4M metabolite was evaluated for 6 of the media that do not utilize it as part of their ingredients. Viable cells were enumerated on Days 10,20, and 30 post inoculation to evaluate performance. The experiment was repeated 3 times using high, low, and medium (trials 1 to 3, respectively) cell concentrations as inoculum. In general there was no optimal medium and all performed well. The choice of which to employ depends on the ease of preparation and presence of certain ingredients that might affect subsequent assays. In trials 2 and 3, the $\mathrm{pH}$ was estimated using test papers at the same time as cells were counted. Maximum pH increase occurred with KDM2+M and those media containing charcoal. For most media, a simple $\mathrm{pH}$ determination could be used as a means to check that growth has occurred in a culture, particularly if charcoal was added directly to the media and a visual inspection could not be made to detect growth.
\end{abstract}

KEY WORDS: Renibacterium salmoninarum - Bacterial Kidney Disease $\cdot$ Broth media Serum free

\section{INTRODUCTION}

Renibacterium salmoninarum, cause of salmonid bacterial kidney disease, is a slow-growing, Grampositive bacterium. It may take weeks or even months to culture this bacterium on primary isolation from fish tissues (Benediktsdóttir et al. 1991, Gudmundsdóttir et al. 1991) and upwards of 2 to $3 \mathrm{wk}$ to produce high cell yields with in vitro cultures. Since the first description of the bacterium, much effort has been given to develop bacteriological media to enhance primary isolation and reduce the incubation time for isolation and growth of in vitro cultures.

The early success in cultivation of Renibacterium salmoninarum can be attributed to the work of Ordal \& Earp (1956). They originally used a medium prepared with minced chick embryo tissues and then they changed to Dorset's medium. Later, using a tryptose blood agar medium supplemented with various nutrients, they found cysteine to be an essential require-

•E-mail: cliff_starliper@usgs.gov ment and this led to the development of cysteine blood agar. It was subsequently found that, although $R$. salmoninarum does not have an absolute requirement for cysteine, use of this amino acid produces better growth than other sulfur-containing amino acids (Daly \& Stevenson 1993).

Wolf \& Dunbar (1959) found success equal to that of cysteine blood agar using a commercially available medium, Mueller Hinton, supplemented with $0.1 \%$ l-cysteine hydrochloride (MHC) and this remained the medium of choice (Bullock et al. 1974) until the development of an improved kidney disease medium that incorporated serum, KDM2 (Evelyn 1977).

Presence of the serum component of KDM2 could result in deleterious effects on subsequent assays. For this reason, and in an effort to reduce cost, other media that do not incorporate complex ingredients such as blood or serum have been devised. Daly \& Stevenson (1985) determined that the function of serum was as a detoxifying agent rather than in providing nutrient value and that activated charcoal may be used to substitute for serum. Shieh (1988) described a complex 
growth medium (SM) that also incorporates activated charcoal, and other media have been developed that do not incorporate either serum or charcoal (Embley et al. 1982, Getchell et al. 1985, Daly \& Stevenson 1993, Teska 1994).

The performance of KDM2 was increased following observation of the characteristic satellite phenomenon of Renibacterium salmoninarum whereby autonomously secreted product(s) further enhance its own growth (Evelyn et al. 1989). This observation soon led to a new medium supplement, metabolite (Evelyn et al. 1990).

The present study evaluated 14 different broth media for growth of Renibacterium salmoninarum; they were prepared without agar because the objective was production and harvest of extracellular growth products, and because a number of studies have already been done to evaluate performance on solid media. Included in the present study were 6 media that were compared pairwise, with and without metabolite from a previous growth culture. Viable cell enumeration was done to evaluate the performance of each medium.

\section{MATERIALS AND METHODS}

Bacteria. Two Renibacterium salmoninarum isolates were used to inoculate the test media: the type strain (ATCC 33209), a 'laboratory' strain, designated so because of repeated transfers and the possibility for medium-specific adaptation; and MCO4M ('field' strain), which had been subcultured only once prior to being frozen and used. Isolate MCO4M was collected in 1991 from kidney tissues of a clinically diseased coho salmon Oncorhynchus kisutch in Lake Michigan. The isolates were maintained in $1 \mathrm{ml}$ aliquots at $-70^{\circ} \mathrm{C}$ until used.

Media. In all, 14 different broth media were evaluated. The same batch of each medium ingredient was used throughout the study. Those media prepared with $1 \% \mathrm{v} / \mathrm{v}$ filter-sterilized Renibacterium salmoninarum MCO4M metabolite were denoted ' $+\mathrm{M}$ ' for this study. One medium, KDM2 (pH 6.5), containing newborn calf serum $(10 \% \mathrm{v} / \mathrm{v})$ and supplemented with metabolite, was used for comparison (denoted KDM2+M). FiveM medium ( $\mathrm{pH}$ 6.5; Teska 1994) was used with 2 slight modifications: first, the antimicrobial agents were omitted since primary isolation was not done, and second, peptone was substituted for tryptone. Each of the following 6 media was evaluated in 2 ways, with $(+\mathrm{M})$ and without metabolite supplementation: $\mathrm{MHC}$ (pH 6.5); charcoal medium $\left(\mathrm{CM}_{\text {; }} \mathrm{pH}\right.$ 6.8; Daly \& Stevenson 1985); peptone/yeast extract/cysteine medium (PYC; pH 6.8; Daly \& Stevenson 1993); the medium of Getchell et al. (1985; GM; pH 6.5), which was KDM2 without serum, but with $0.0057 \%$ ferric sulphate; the medium of Shieh $\left(1988 ; \mathrm{SM}_{i} \mathrm{pH} 7.0\right)_{\text {; }}$ and the semidefined medium of Embley et al. (1982; EM; pH 6.8). For those media that contain charcoal $(C M, C M+M$, $\mathrm{SM}, \mathrm{SM}+\mathrm{M})$, this ingredient was added directly to the broth. Serum and metabolite were added after autoclaving, to cooled media.

Growth and quantification. The same growth conditions and growth chamber were utilized for preparation of inocula and during conduct of the $30 \mathrm{~d}$ growth trials. A $1 \mathrm{ml}$ aliquot of either Renibacterium salmoninarum isolate was thawed and used to inoculate $50 \mathrm{ml}$ of $\mathrm{KDM} 2+\mathrm{M}$ in a $250 \mathrm{ml}$ flask. Following incubation at $15^{\circ} \mathrm{C}$ on a shaker $(100 \mathrm{rpm})$ for $21 \mathrm{~d}$, viable cells were quantified (Miles \& Misra 1938) by preparing 10-fold serial dilutions in $\mathrm{KDM} 2+\mathrm{M}$ without l-cysteine (Starliper 1996) and plating on KDM2+M agar plates. Subsequent bacterial colonies were counted and the number of cells reported as colony forming units per ml (cfu $\mathrm{ml}^{-1}$ ). To remove serum, the cells of the $50 \mathrm{ml}$ culture were centrifuged for $30 \mathrm{~min}$ at $5000 \times g$ in a Sorvall $\mathrm{RC} 2-\mathrm{B}$ at $4^{\circ} \mathrm{C}$, the supernatant was discarded and the cells were resuspended with $50 \mathrm{ml} 1 \%$ peptonef $0.05 \%$ yeast extract ( $\mathrm{pH} 7.0$ ). This cell suspension was used as the seed inoculum for the test media. Six replicate flasks of each of the 14 test media were inoculated with $0.5 \mathrm{ml}$ seed inoculum per flask $(1 \%, \mathrm{v} / \mathrm{v})$. Each medium was prepared, then $50 \mathrm{ml}$ aliquots were added to $250 \mathrm{ml}$ flasks. All test media were incubated at $15^{\circ} \mathrm{C}$ on a shaker at $100 \mathrm{rpm}$. At 10,20, and $30 \mathrm{~d}$ post inoculation, a $1 \mathrm{ml}$ aliquot was removed from each test flask for viable cell enumeration. Serial 10 -fold dilutions were prepared in $\mathrm{KDM} 2+\mathrm{M}$ without l-cysteine and viable cell counting was done as previously described for the inoculum culture. On each sample day, each aliquot was also used to streak-inoculate plates of brain heart infusion agar (BHIA; Difco Laboratories, Detroit, MI, USA) to check for lack of growth which would indicate that bacteria other than $R$. salmoninarum were not present. It was noted during trial 1 that the results of occasional $\mathrm{pH}$ testing on growth cultures indicated a $\mathrm{pH}$ increase with length of incubation. Therefore, the $\mathrm{pH}$ of all aliquots from trials 2 and 3 was estimated by blotting $0.02 \mathrm{ml}$ onto $\mathrm{pH}$ test paper (Micro Essential Laboratories, Brooklyn, NY, USA). Resulting colour of the test paper was compared to the colour standard provided. For consistency in interpretation of the colour changes, the same person (J.M.) estimated all $\mathrm{pH}$ values.

Growth trials. Three trials differed in the number of viable cells used for the inoculum. High and low concentrations of ATCC 33209 cells (trials 1 and 2, respectively) were used to inoculate test media and evaluate growth performance using a laboratory strain that had undergone repeated transfers prior to use. In the first 
(trial 1), undiluted ATCC 33209 cells were used to inoculate each test flask. The viable cell count of this inoculum was $1.128 \times 10^{8} \mathrm{cfu} \mathrm{ml}^{-1}$; therefore, each flask contained about $1.128 \times 10^{6} \mathrm{cfu} \mathrm{m}^{-1}$ at the start of the trial. For trial 2, resuspended ATCC 33209 cells $\left(1.34 \times 10^{8} \mathrm{cfu} \mathrm{m}^{-1}\right)$ were diluted 1:50 in peptone-yeast extract broth and this was then used as the inoculum, with each test flask containing approximately $2.68 \times$ $10^{4} \mathrm{cfu} \mathrm{m}^{-1}$ at the start. Flasks of trial 3 were inoculated with MCO4M cells $\left(2.45 \times 10^{8} \mathrm{cfu} \mathrm{ml}^{-1}\right)$ that were diluted 1:20 in peptone-yeast extract broth, resulting in test flasks containing about $1.23 \times 10^{5} \mathrm{cfu} \mathrm{ml}^{-1}$ at the start of the trial.

Statistical analysis. Resulting data were analyzed by evaluating, for each trial, only the highest mean viable cell count for each medium without consideration of the day (either 10,20 or 30) that yielded that count. A single factor analysis of variance (ANOVA; $\alpha=0.05$ ) was performed to determine if a significant difference of variances between media was greater than that within replicates of each medium $\left(F_{\text {stat }}\right)$, and this was compared to a critical value $\left(F_{\text {crt }}\right)$. Pairwise comparisons of those media prepared with and without supplementation with metabolite were done using a $t$-test to determine if metabolite affected growth. Statistical analyses were done using Excel Version 7.0 (Microsoft Corp.) and NCSS 97 (Kaysville, UT, USA).

\section{RESULTS}

The mean cfu $\mathrm{ml}^{-1}$ for 6 replicates of each medium at 10,20 , and $30 \mathrm{~d}$ for the 3 trials is provided in Tables 1 to 3 . In trial 1, 6 flasks were lost to contamination after the $10 \mathrm{~d}$ count as indicated by growth on BHIA plates; 1 flask became contaminated during trial 2 ; and none in trial 3 was contaminated. Within each of Tables 1 to 3 (trials 1 to 3 , respectively), media are listed in descending order beginning with the highest mean $\mathrm{cfu} \mathrm{ml}^{-1}$ (by peak day) recorded throughout the $30 \mathrm{~d}$ period.

Trial 1 flasks were inoculated at $1 \%$ $(\mathrm{v} / \mathrm{v})$ of the seed culture which was the highest starting $\mathrm{cfu} \mathrm{ml} \mathrm{m}^{-1}$. This was reflected in the resulting growth, as the peak day was 10 for 11 of 14 media. The highest growth was with GM at $4.85 \times 10^{9} \mathrm{cfu} \mathrm{ml}^{-1}$, and this was higher than that for $G M+M$, which was the second highest at less than half, $2.32 \times$

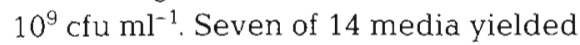
counts greater than $1 \times 10^{9} \mathrm{cfu} \mathrm{ml} \mathrm{m}^{-1}$, and all but $3(\mathrm{CM}, \mathrm{CM}+\mathrm{M}, \mathrm{EM}+\mathrm{M})$
Table 1. (Trial 1). Mean viable cell counts ( $\mathrm{cfu} \mathrm{m} \mathrm{l}^{-1}$ ) of Renibacterium salmoninarum ATCC 33209 grown in 14 different media, with 6 replicates for each. Media are listed from highest to lowest cell count (according to peak day) during the $30 \mathrm{~d}$ growth period. Each flask contained about $1.128 \times 10^{\mathrm{b}} \mathrm{cfu}$ $\mathrm{ml}^{-1}$ at the start

\begin{tabular}{|c|c|c|c|c|}
\hline Medium ${ }^{\mathrm{d}}$ & Day 10 & Day 20 & Day 30 & Peak day \\
\hline GM & $4.85 \times 10^{9}$ & $2.35 \times 10^{5}$ & $2.84 \times 10^{2}$ & 10 \\
\hline $\mathrm{GM}+\mathrm{M}$ & $2.32 \times 10^{9}$ & $4.82 \times 10^{5}$ & $1.23 \times 10^{3}$ & 10 \\
\hline $\mathrm{PYC}+\mathrm{N}_{1}$ & $2.12 \times 10^{9}$ & $1.01 \times 10^{3}$ & $0.00 \times 10^{0}$ & 10 \\
\hline $\mathrm{SM}+\mathrm{M}$ & $1.56 \times 10^{9}$ & $5.50 \times 10^{1}$ & $0.00 \times 10^{0}$ & 10 \\
\hline SM & $1.48 \times 10^{9}$ & $6.50 \times 10^{5}$ & $0.00 \times 10^{0}$ & 10 \\
\hline FiveM & $1.38 \times 10^{9}$ & $6.71 \times 10^{5}$ & $1.12 \times 10^{4}$ & 10 \\
\hline EM & $6.97 \times 10^{5}$ & $1.23 \times 10^{9}$ & $3.71 \times 10^{8}$ & 20 \\
\hline $\mathrm{KDM} 2+\mathrm{M}$ & $7.29 \times 10^{8}$ & $1.56 \times 10^{3}$ & $3.33 \times 10^{0}$ & 10 \\
\hline PYC & $9.73 \times 10^{4}$ & $2.55 \times 10^{8}$ & $5.48 \times 10^{8}$ & 30 \\
\hline $\mathrm{MHC}$ & $4.65 \times 10^{8}$ & $1.14 \times 10^{6}$ & $3.57 \times 10^{5}$ & 10 \\
\hline $\mathrm{MHC}+\mathrm{M}$ & $1.67 \times 10^{8}$ & $5.25 \times 10^{5}$ & $1.05 \times 10^{3}$ & 10 \\
\hline $\mathrm{CM}$ & $8.29 \times 10^{6}$ & $0.00 \times 10^{0}$ & $0.00 \times 10^{0}$ & 10 \\
\hline $\mathrm{CM}+\mathrm{M}$ & $4.07 \times 10^{6}$ & $0.00 \times 10^{0}$ & $0.00 \times 10^{0}$ & 10 \\
\hline $\mathrm{EM}+\mathrm{M}$ & $0.00 \times 10^{0}$ & $5.67 \times 10^{1}$ & $0.00 \times 10^{0}$ & 20 \\
\hline \multicolumn{5}{|c|}{$\begin{array}{l}\text { "Medium name: GM, Getchell et al. (1985); PYC, Daly \& } \\
\text { Stevenson (1993); SM, Shieh (1988); FiveM, Teska (1994); } \\
\text { EM, Embley et al. (1982); KDM2+M, Evelyn (1977), Eve- } \\
\text { lyn et al, (1990); MHC, Wolf \& Dunbar (1959); CM, Daly } \\
\& \text { Stevenson (1985). Six media were evaluated with } \\
\text { metabolite, denoted '+M' }\end{array}$} \\
\hline
\end{tabular}

yielded mean cell counts greater than $1 \times 10^{8} \mathrm{cfu} \mathrm{ml}^{-1}$. On Day 30, no viable cells were cultured from 5 of the media (Table 1). The ANOVA for the peak day mean counts of trial 1 data was significant, $F_{\text {stat }}=8.94 \mathrm{com}-$ pared to $F_{c r i t}=1.86\left(\mathrm{df}_{1}=13, \mathrm{df}_{2}=70\right)$. There was barely any growth with 1 medium $(\mathrm{EMB}+\mathrm{M})$, with a peak viable cell count of $5.67 \times 10^{1} \mathrm{cfu} \mathrm{m}^{-1}$ on Day 20 and no cells isolated on either of Days 10 or 30. Pair-

Table 2. (Trial 2). Mean viable cell counts ( $\mathrm{cfu} \mathrm{m} \mathrm{m}^{-1}$ ) of Renibacterium salmoninarum ATCC 33209 grown in 14 different media, with 6 replicates for each. Media are listed from highest to lowest cell count (according to peak day) during the $30 \mathrm{~d}$ growth period. Each flask contained about $2.68 \times 10^{4} \mathrm{cfu} \mathrm{m}^{-1}$ at the start. The mean estimated $\mathrm{pH}$ is given in parentheses

\begin{tabular}{|lcccc|}
\hline Medium $^{a}$ & Day 10 & Day 20 & Day 30 & Peak day \\
\hline PYC & $3.20 \times 10^{3}(6.87)$ & $6.28 \times 10^{3}(7.00)$ & $4.60 \times 10^{5}(6.84)$ & 30 \\
GM & $8.07 \times 10^{3}(6.75)$ & $9.25 \times 10^{4}(6.50)$ & $2.67 \times 10^{4}(6.72)$ & 20 \\
CM+M & $5.25 \times 10^{4}(7.32)$ & $7.90 \times 10^{4}(7.62)$ & $4.03 \times 10^{4}(7.43)$ & 20 \\
FiveM & $1.78 \times 10^{4}(6.98)$ & $2.12 \times 10^{4}(6.90)$ & $3.73 \times 10^{4}(6.97)$ & 30 \\
MHC+M & $8.87 \times 10^{3}(6.80)$ & $2.58 \times 10^{4}(6.70)$ & $3.59 \times 10^{4}(6.77)$ & 30 \\
CM & $3.10 \times 10^{4}(7.10)$ & $2.36 \times 10^{4}(7.75)$ & $2.37 \times 10^{4}(7.98)$ & 10 \\
MHC & $1.95 \times 10^{4}(6.65)$ & $2.54 \times 10^{4}(6.65)$ & $2.93 \times 10^{4}(6.80)$ & 30 \\
GM+M & $9.80 \times 10^{3}(6.83)$ & $2.33 \times 10^{4}(6.50)$ & $2.65 \times 10^{4}(6.90)$ & 30 \\
EM & $9.77 \times 10^{2}(6.98)$ & $1.26 \times 10^{4}(6.88)$ & $2.01 \times 10^{4}(6.95)$ & 30 \\
KDM2+M & $1.32 \times 10^{4}(7.87)$ & $5.33 \times 10^{3}(7.67)$ & $8.83 \times 10^{3}(7.90)$ & 10 \\
EM+M & $4.08 \times 10^{3}(6.90)$ & $7.28 \times 10^{3}(6.80)$ & $1.06 \times 10^{4}(6.90)$ & 30 \\
SM & $3.71 \times 10^{3}(7.75)$ & $4.13 \times 10^{3}(7.92)$ & $5.74 \times 10^{3}(7.82)$ & 30 \\
PYC+M & $1.51 \times 10^{3}(6.87)$ & $3.74 \times 10^{3}(6.87)$ & $3.84 \times 10^{3}(6.97)$ & 30 \\
SM+M & $2.20 \times 10^{3}(7.75)$ & $2.32 \times 10^{3}(7.75)$ & $2.07 \times 10^{3}(7.77)$ & 20 \\
aSee Table 1 for identification of media & & \\
\hline
\end{tabular}


Table 3. (Trial 3). Mean viable cell counts ( $\mathrm{cfu} \mathrm{m}^{-1}$ ) of Renibacterium salmoninarum MCO4M grown in 14 different media, 6 replicates for each. Media are listed from highest to lowest cell count (according to peak day) during the $30 \mathrm{~d}$ growth period. Each flask contained about $1.23 \times 10^{5} \mathrm{cfu} \mathrm{ml}^{-1}$ at the start. The mean estimated $\mathrm{pH}$ of the cultures is given in parentheses

\begin{tabular}{|lcccc|}
\hline Medium $^{2}$ & Day 10 & Day 20 & Day 30 & Peak day \\
\hline FiveM & $2.02 \times 10^{9}(7.82)$ & $1.24 \times 10^{6}(7.98)$ & $2.11 \times 10^{4}(8.92)$ & 10 \\
EM & $8.75 \times 10^{4}(6.83)$ & $3.12 \times 10^{7}(6.78)$ & $1.70 \times 10^{9}(7.03)$ & 30 \\
CM+M & $1.20 \times 10^{9}(8.40)$ & $3.21 \times 10^{4}(8.75)$ & $5.56 \times 10^{4}(8.92)$ & 10 \\
CM & $1.07 \times 10^{9}(8.65)$ & $1.16 \times 10^{5}(8.22)$ & $2.95 \times 10^{4}(8.35)$ & 10 \\
MHC & $7.76 \times 10^{8}(7.20)$ & $9.39 \times 10^{6}(8.17)$ & $3.05 \times 10^{5}(8.43)$ & 10 \\
GM & $5.05 \times 10^{8}(7.55)$ & $1.34 \times 10^{7}(8.48)$ & $1.77 \times 10^{4}(8.42)$ & 10 \\
GM+M & $4.59 \times 10^{8}(8.17)$ & $1.21 \times 10^{4}(8.28)$ & $1.40 \times 10^{4}(8.82)$ & 10 \\
EM+M & $2.35 \times 10^{3}(6.83)$ & $8.55 \times 10^{4}(6.83)$ & $3.94 \times 10^{8}(6.77)$ & 30 \\
PYC+M & $1.38 \times 10^{7}(6.97)$ & $3.80 \times 10^{8}(8.27)$ & $4.87 \times 10^{5}(8.98)$ & 20 \\
MHC+M & $3.28 \times 10^{8}(7.03)$ & $8.08 \times 10^{7}(8.37)$ & $7.40 \times 10^{4}(8.57)$ & 10 \\
SM+M & $2.56 \times 10^{7}(7.13)$ & $2.45 \times 10^{8}(8.08)$ & $1.44 \times 10^{4}(7.93)$ & 20 \\
KDM2+M & $1.65 \times 10^{8}(7.65)$ & $5.95 \times 10^{6}(7.83)$ & $6.65 \times 10^{5}(8.13)$ & 10 \\
SM & $1.53 \times 10^{8}(7.40)$ & $2.84 \times 10^{7}(7.97)$ & $2.32 \times 10^{3}(7.82)$ & 10 \\
PYC & $1.05 \times 10^{5}(6.92)$ & $9.79 \times 10^{4}(6.73)$ & $6.07 \times 10^{7}(6.62)$ & 30 \\
ISee Table 1 for identification of media & & \\
\multicolumn{7}{l}{ I } & & \\
\hline
\end{tabular}

wise comparisons of the 6 media in trial 1 that were prepared with and without metabolite were done, and 2 media ( $P Y C, M H C$ ) showed significant differences. In 1 comparison, $\mathrm{PYC}+\mathrm{M}$ produced a higher mean count than PYC alone ( $\mathrm{p}=0.0003)$; however, $\mathrm{MHC}$ gave a higher mean cell count than did $M H C+M(p=0.0524)$.

The seed culture used for trial 2 was more dilute $(1: 50)$ than for trial 3 , in an attempt to increase the sensitivity of the growth response, or to give only those media that were optimum for growth of Renibacterium salmoninarum an opportunity to outperform others. It was found that with this small inoculum growth of the bacterium was retarded throughout the $30 \mathrm{~d}$ trial relative to the mean cell yields of the other 2 trials. The highest cell number in trial 2 was $4.60 \times 10^{5} \mathrm{cfu} \mathrm{ml}^{-1}$, grown in PYC medium (Table 2); whereas in trial 3, PYC produced the lowest cell yield. The lowest mean cell growth was with $\mathrm{SM}+\mathrm{M}, 2.32 \times 10^{3} \mathrm{cfu} \mathrm{ml^{-1 }}$ In trials 1 and 3, for most media the peak day was Day 10; however, with the decreased inoculum in trial 2, only 1 medium (KDM2+M) peaked on Day 10. The peak day for 9 of 14 media was Day 30. An ANOVA on trial 2 was not significant, $F_{\text {stat }}=1.15$ compared to $F_{\text {crit }}=1.87$ with $\mathrm{df}_{1}=13$ and $\mathrm{df}_{2}=68$. Furthermore, metabolite supplementation failed to produce increased growth because, as indicated by the ANOVA, none of the pairwise comparisons of media with and without metabolite differed. Concurrent with lesser culture growth in trial 2 was a lesser increase in alkalinity. The $\mathrm{pH}$ of most culture media remained nearly the same as prior to inoculation, with the greatest increases occurring in $\mathrm{KDM} 2+\mathrm{M}, \mathrm{CM}, \mathrm{CM}+\mathrm{M}, \mathrm{SM}$, and $\mathrm{SM}+\mathrm{M}$.

The test flasks of trial 3 were inoculated with a 1:20 dilution of the seed culture. Five of 14 of the mean viable cell counts peaked on either Day 20 or 30 (Table 3) compared to 3 of 14 in trial 1. The highest mean was with FiveM on Day 10, $2.02 \times 10^{9} \mathrm{cfu}$ $\mathrm{ml}^{-1}$, and the lowest was with PYC, $6.07 \times 10^{7} \mathrm{cfu} \mathrm{m}^{-1}$ on Day 30. Four media (FiveM, EM, CM+M, CMI) yielded mean cell counts greater than $1 \times 10^{9} \mathrm{cfu} \mathrm{m}^{-1}$. Only 1 medium (PYC) yielded a mean cell count of less than $1 \times 10^{8} \mathrm{cfu} \mathrm{ml}^{-1}$. An ANOVA determined that there was at least 1 medium that produced a significantly different growth $\left(F_{\text {stat }}=3.93\right)$ compared to $F_{\text {crt }}=1.86$ with $\mathrm{df}_{1}=13$ and $\mathrm{df}_{2}=70$. Two media (FiveM, EM) produced the highest cell numbers; however, for FiveM the peak day was Day 10, whereas for EMî the peak day for cell numbers was Day 30. With the lower number of cells used in the seed inoculum for this trial (relative to trial 1), there were 3 of 6 pairwise comparisons of media with and without metabolite that differed. As with trial 1, growth in PYC $(p=0.0076)$ and $M H C(p=0.0142)$ was different from in $\mathrm{PYC}+\mathrm{M}$ and $\mathrm{MHC}+\mathrm{M}$, respectively. In addition, $\mathrm{EM}$ $(p=0.0258)$ produced significantly more growth than did $E M+M$. Of these 3 comparisons, only PYC displayed a greater mean cell count with metabolite supplementation, as it did in trial 1. The $\mathrm{pH}$ of cultures of 11 of 14 media became alkaline during the $30 \mathrm{~d}$ growth period, and approached $\mathrm{pH} 9.0$ in some media, namely: FiveM, CM+M, and PYC+M (Table 3). The $\mathrm{pH}$ of other media also increased, but to a lesser extent. With 3 media (EM, EM+M, PYC), the pH remained similar to uninoculated media, yet the mean cell yields at Day 30 were similar in range to those of the other media (at Day 10). As pH increased in most media over the $30 \mathrm{~d}$ period, mean viable cell numbers were in decline with time. Interestingly, the peak day of cell yield was Day 30 for only those 3 media for which $\mathrm{pH}$ remained relatively low.

\section{DISCUSSION}

Although not all achieved their highest cell numbers on the same day, many of the media yielded similar performances as indicated by mean cfu $\mathrm{ml}^{-1}$. Therefore, the medium of choice may depend on the intended use for the resulting growth culture as certain of the media might contain components that affect or interfere with subsequent assays. For example, the charcoal contained in CM and SM media might impede collection of bacteria if the charcoal is incorpo- 
rated into the media as it was for this study. However, this could be eliminated if the charcoal were placed in dialysis tubing, or perhaps not used at all when broth cultures are shaken (Daly \& Stevenson 1993).

FiveM medium utilizes metabolite, thus requiring that a culture be previously grown and the metabolite harvested. Most of the media are simple and straightforward to prepare; however, SM and EM have extra ingredients and, therefore, are inherently more difficult to prepare. Other considerations when selecting a medium may be whether filtered ingredients need to be added to cooled media thereby increasing the risk of contamination, and the inoculum achievable or likely to be present.

In our comparisons of each medium with and without supplementation with metabolite, we did not, in general, note a significant outcome from using metabolite, except that in trials 1 and $3, P Y C+M$ gave higher mean cell counts than did PYC, and in contrast, $\mathrm{MHC}$ gave higher mean cell counts than did $\mathrm{MHC}+\mathrm{M}$. We surmise that our experimental design (use of shaken broth cultures) might have affected any potential advantage to incorporating metabolite. The effect of metabolite would likely not be as pronounced in broth media on a shaker as it would on agar media since the growth components produced would be kept evenly dispersed in the broth. Based on previous studies in our laboratory, incorporation of $21 \mathrm{~d}$ old metabolite into agar media significantly enhances growth, which was previously shown by Evelyn et al. (1990) using metabolite from an 18 d culture. More recently, Evelyn \& ProsperiPorta (1992) showed that metabolite from a $30 \mathrm{~d}$ culture was superior to $18 \mathrm{~d}$. We do not know how our $21 \mathrm{~d}$ metabolite performed relative to the 30 d of Evelyn \& Prosperi-Porta (1992) because we did not do parallel experiments in the present study using agar media. However, if $30 \mathrm{~d}$ metabolite is superior to $21 \mathrm{~d}$ as well, then we may have noted a more pronounced effect with the older metabolite, particularly in trial 2 which received our lowest cell concentration as inoculum. Results with FiveM medium indicate that a liberal amount of metabolite might be used to replace serum or charcoal.

For most of the media for which peak culture growth occurred on Day 10, particularly those in trial 1, there was a significant decrease in the mean cell counts by Day 20. No viable cells were isolated in trial 1 on Day 30 from 5 media, yet cultures remained turbid and would still yield a high optical density reading. It is likely that the inoculum of trial 1 was sufficiently heavy to result in rapid growth in many flasks, leading to depletion of nutrients and extinction of cultures. In trials 2 and 3 the seed cultures were diluted prior to use to increase sensitivity in detecting differences in growth response. The effect of this was evident be- cause Day 10 was less frequently the peak day, and more important, in trials 2 and 3 there were no null mean viable cell counts. Several of our $10 \mathrm{~d}$ counts were lower than the initial cfu $\mathrm{ml}^{-1}$, particularly in with trial 2 (Table 2). In this trial, each test flask contained about $2.68 \times 10^{4} \mathrm{cfu} \mathrm{m}^{-1}$ at the start and by Day 10 mean counts were lower for 12 of 14 media. This could be a characteristic of the use of broth media. Evelyn \& Prosperi-Porta (1992) did a comparative growth study with Renibacterium salmoninarum using agar media; their number of cells used for inoculum, estimated by turbidity, was only slightly higher and they obtained good growth response. Perhaps an advantage of drop inoculation on plates is that as cells multiply they produce metabolite which remains proximate and thereby increases the concentration of available growth-enhancing material. In broth, autonomously secreted extracellular growth products are effectively diluted.

The pH of cultures in trials 2 and 3 was determined at the same time as viable cell enumeration to evaluate whether alkalinity could be used as an indicator of growth, particularly for those media that contained charcoal (CM, CM+M, SM, SM+M), where visual inspection could not be used as an indication of growth. Our results indicated that an increase in pH could be used as simple evidence for bacterial growth, particularly for those media that contained charcoal. This could be done by aseptically removing a small aliquot and placing it on a piece of $\mathrm{pH}$ test paper. In trial 3, which yielded much better overall growth than trial 2 , a significant increase in $\mathrm{pH}$ occurred in all media except for EM, EM+M, and PYC (Table 3). Therefore, with these few media, a stable $\mathrm{pH}$ does not imply that growth has not occurred, but on the other hand these media did not have charcoal and visual inspection would suffice. In trial 3 , the maximum $\mathrm{pH}$ values we recorded occurred in older cultures (20 and $30 \mathrm{~d}$ ) and this is comparable to the study by Evelyn \& ProsperiPorta (1992), which showed that metabolite from older (30 d) cultures was better for stimulating subsequent growth. With trial 2 increases were more subtle, and the highest increases were recorded for KDM2+M and the media with charcoal. For most media, increased $\mathrm{pH}$ seemed to be a reliable indicator that growth had occurred. For those media in trial 3 that displayed increasing $\mathrm{pH}$, the $\mathrm{PH}$ increased throughout the growth period or was high on Day 20 and remained similarly high on Day 30 . At the same time, the mean viable cell counts were decreasing with time. The alkaline $\mathrm{pH}$ shift could be a result of metabolism of protein(s) or a significant increase in the number of dead cells. In contrast, stable $\mathrm{pH}$ throughout a trial could indicate minimal culture growth or stronger buffering capacity of the medium. 
The performance of these media might differ significantly from that described here for the recovery of cultures from storage or for isolation of the bacterium from fish. Addition of serum and/or metabolite to culture media may be helpful in recovering weakened bacteria. Another possibie influence on results of this study is that, since our inoculum was grown in $\mathrm{KDM} 2+\mathrm{M}$, and a number of our media had the same basal components as KDM2+M (peptone, yeast extract, l-cysteine), growth might have been positively affected by adaptation of the bacterium. Growth in a medium with different basal ingredients might be enhanced if the inoculum was also grown in that same medium

Acknowledgements. The authors appreciate the critical review of this manuscript provided by Drs Vicki Blazer, G. L. Bullock and Emmett B. Shotts, Jr.

\section{LITERATURE CITED}

Benediktsdóttir E, Helgason S, Gudmundsdóttir S (1991) Incubation time for the cultivation of Renibacterium salmoninarum from Atlantic salmon, Salmo salar L., broodfish. J Fish Dis 14:97-102

Bullock GL, Stuckey HM, Chen PK (1974) Corynebacterial kidney disease of salmonids: growth and serological studies on the causative bacterium. Appl Microbiol 28: $811-814$

Daly JG, Stevenson RMW (1985) Charcoal agar, a new growth medium for the fish disease bacterium Renibacterium salmoninarum. Appl Environ Microbiol 50:868-871

Daly JG, Stevenson RMW (1993) Nutrient requirements of Renibacterium salmoninarum on agar and in broth media. Appl Environ Microbiol 59:2178-2183

Embley TM, Goodfellow M. Austin B (1982) A semi-defined growth medium for Renibacterium salmoninarum. FEMS Microbiol Lett 14:299-301

Evelyn TPT (1977) An improved growth medium for the

Editorial responsibility: David Bruno,

Aberdeen, Scotland, UK kidney disease bacterium and some notes on using the medium. Bull Off Int Epizoot 87:511-513

Evelyn TPT, Bell GR, Prosperi-Porta L, Ketcheson JE (1989) A simple technique for accelerating the growth of the kidney disease bacterium Renibacterium saimoninarum on a commonly used culture medium (KDM2). Dis Aquat Org $7: 231-234$

Evelyn TPT, Prosperi-Porta L (1992) A new medium for growing the kidney disease bacterium: its performance relative to that of other currently used media. In: Kimura $T$ (ed) Salmonid diseases. Hokkaido University Press, Sapporo, p $143-150$

Evelyn TPT, Prosperi-Porta L, Ketcheson JE (1990) Two new techniques for obtaining consistent results when growing Renibacterium salmoninarum on KDM2 culture medium. Dis Aquat Org 9:209-212

Getchell RG, Rohovec JS, Fryer JL (1985) Comparison of Renibacterium salmoninarum isolates by antigenic analysis. Fish Pathol 20:149-159

Gudmundsdóttir S, Helgason S, Benediktsdóttir E (1991) Comparison of the effectiveness of three different growth media for primary isolation of Renibacterium salmoninarum from Atlantic salmon, Salmo salar L., broodfish. J Fish Dis 14:89-96

Miles AA, Misra SS (1938) The estimation of the bactericidal power of the blood. J Hygiene 38:732-749

Ordal EJ, Earp BJ (1956) Cultivation and transmission of etiological agent of kidney disease in salmonid fishes. Proc Soc Exp Biol Med 92:85-88

Shieh HS (1988) Blood-free media for the cultivation of the fish kidney disease bacterium, Renibacterium salmoninarum. Microbios Lett 37:141-145

Starliper CE (1996) Comparison of four cell diluents to determine viable counts of Renibacterium salmoninarum. Biomed Lett 53:139-147

Teska JD (1994) In vitro growth of the bacterial kidney disease organism Renibacterium salmoninarum on a nonserum, noncharcoal-based 'homospecies-metabolite' medium. $J$ Wildlife Dis 30:383-388

Wolf K, Dunbar CE (1959) Methods of infecting trout with kidney disease and some effects of temperature on experimental infections. U. S. Department of Interior, Special Scientific Report, Fisheries no. 286, Washington, DC

Submitted: February 9, 1998; Accepted: June 13, 1998

Proofs received from author(s): August 28, 1998 